\title{
FASILITAS KREATIVITAS DAUR ULANG KAYU
}

\author{
Sonia Fernanda ${ }^{1)}$, Rudy Surya ${ }^{2)}$ \\ 1)Program Studi S1 Arsitektur, Fakultas Teknik, Universitas Tarumanagara, soniafnd15@gmail.com \\ 2) Program Studi S1 Arsitektur, Fakultas Teknik, Universitas Tarumanagara, rudys@ftuntar.ac.id
}

\begin{abstract}
Abstrak
Pada dewasa ini pemanfaatan kayu di Indonesia mengalami tantangan yang cukup berat karena adanya ketimbangan antara bahan baku yang ada dengan bahan baku yang dibutuhkan. Oleh karena itu, dengan Karakteristik Generasi Milenial yang kreatif dan aktif dapat membantu dalam memaksimalkan pemanfaatan kayu dan limbah yang mengarah kepada zero limbah. Proyek ini memiliki tujuan untuk mewadahi para pengrajin kayu dan juga generasi milenial untuk dapat memanfaatkan limbah kayu menjadi suatu produk baru yang bermanfaat dan dapat mengundang para pelaku wirausaha baru untuk mulai berwirausaha dalam sektor daur ulang kayu. Dengan mengambil konsep Creative hub dimana para ahli pengrajin kayu dan juga para pelaku wirausaha baru dapat berkumpul dan bekerja sama dalam menghasilkan suatu produk yang dibutuhkan sekarang ini. Kelompok kegiatan yangg ada dibuat berdasarkan zoning dan juga kebutuhan dari setiap ruangan yang ada. Produk daur Ulang yang dibuat dibedakan dalam 2 tipe ruangan yang berbeda berdasakan ukuran barang yang dibuat. Diharapkan bangunan ini dapat menghidupkan kembali kawasan sekitar dan juga mengundang masyarakat untuk mau lebih mengenal lagi mengenai daur ulang kayu.
\end{abstract}

Kata kunci: Daur; Kayu; Kreatif; Milenial

\begin{abstract}
At present, the use of wood in Indonesia faces quite a challenge because of the imbalance between existing raw materials and the raw materials needed. Thus, with the creative and active Characteristics of the Millennial Generation can help in maximizing the use of wood and waste which leads to zero waste. This project aims to accommodate wood craftsmen and millennial to be able to use wood waste to become a useful new product and can invite new entrepreneurs to start entrepreneurship in the wood recycling sector. By taking the Creative hub concept where wood craftsmen and new entrepreneurs can gather and work together to produce a product that is needed today. The existing activity groups are based on zoning and also the needs of each room. Recycled products are made in two different types of rooms based on the size of the items made. It is hoped that this building can revive the surrounding area and also invite the public to want to know more about wood recycling.
\end{abstract}

Keywords: Creative; Millenial; Recycling; Wood

\section{PENDAHULUAN}

Jakarta merupakan kota metropolitan sekaligus sebagai pusat dari segala kesibukan. Lebih dari 33\% penduduk Indonesia adalah penduduk muda yang berusia 15 - 34 tahun, bahkan untuk daerah perkotaaan seperti DKI Jakarta penduduk mudanya bisa mencapai lebih dari 40\%[1]. Mereka inilah yang kemudian dikenal sebagai generasi milenial.

Menurut Todd Cherches dari The Hired Guns mengungkapkan bahwa secara rata- rata anak milenial memiliki toleransi yang rendah terhadap proses yang lama. Mereka menolak melakukan suatu pekerjaan yang monoton karena mereka fokus terhadap apa yang perlu diselesaikan dengan mencari cara sendiri. Artinya mereka bukannya tidak mau bekerja tapi mereka memiliki cara kerja yang berbeda. Selain itu generasi millenials juga lebih menginginkan pekerjaan yang memiliki waktu yang lebih fleksibel dan dinamis karena waktu bekerja dari jam 9 sampai 5 sore dinilai tidaklah lagi efektif. Generasi Milenial lebih menginginkan untuk bekerja jarak jauh sehingga rasa tertekan dalam bekerja akan lebih 
berkurang. Dilansir New York Post, sekitar 57 persen pekerja kantoran modern di Amerika Serikat merasa lebih produktif dengan bekerja jarak jauh dan tidak dituntut bekerja di waktu tertentu. Dengan karakter Generasi Milenial ini, Wirausaha dapat dijadikan pertimbangan dalam memilih profesi karena wirausaha dinilai sebagai pekerjaan yang tepat bagi Generasi Milenial

Yoris Sebastian dalam bukunya berjudul "Generasi Langgas Milenials Indonesia" mengatakan bahwa generasi millenials sebagai wirausaha di era digital ini masi sangatlah rendah. Banyak dari generasi millenials ini yang memiliki keinginan untuk mempunyai usaha sendiri tapi masih sedikit sekali dari generasi ini yang sudah mewujudkan keinginannya untuk menjadi wirausaha.

Berdasarkan hasil survey yang dilakukan oleh HIPMI di berbagai perguruan tinggi, animo dan minat lulusan S1 yang menginginkan untuk menjadi wirausaha hanya sebesar $4 \%$ dengan $83 \%$ mahasiswa di Indonesia masih menginginkan untuk menjadi karyawan dan 13\% mahasiswa ingin bekerja di birokrat.

Sedangkan diperkirakan pada tahun 2030, Indonesia diperkirakan akan mencapai puncak bonus demografi. Pada rentang 2020-2035, Indonesia mendapat bonus demografi dengan jumlah kelompok usia produktif, yakni usia 15-64 tahun, jauh melebihi kelompok usia tidak produktif (usia 14 tahun ke bawah 65 tahun ke atas). Yang artinya nanti pada tahun 2030 generasi ini akan bersaing dalam mendapatkan pekerjaan karena peningkatan jumlah lapangan pekerjaan yang ada tidak sebanding dengan jumlah pencari kerja yang ada.

Oleh Karena itu, Salah satu program yang sedang dijalankan pemerintah adalah menggalakan pertumbuhan entrepreneur muda di Indonesia. Hal ini disebabkan karena peran dari Wirausaha Muda ini sangatlah penting dalam membantu pertumbuhan ekonomi. Selain memiliki andil dalam penciptaan lapangan kerja, para wirausahawan juga turut memberikan dukungan terhadap pertumbuhan ekonomi melalui bidang usahanya masing-masing. Pemerintah menilai, perkembangan teknologi digital yang begitu pesat dapat memunculkan banyak wirausahawan muda yang sukses di Indonesia.

Dalam proyek tugas akhir ini, dengan tujuan membantu program pemerintah untuk mencapai peningkatan perekonomian di Indonesia. Bagaimana dengan mulai memberikan berbagai pengetahuan serta dukungan terhadap Generasi Millenial mengenai wirausaha di ekonomi kreatif ini agar dapat memasarkan produk- produknya lebih luas dan juga dapat melakukan inovasi- inovasi yang dapat disesuaikan dengan era ekonomi kreatif sekarang ini sehingga tidak kalah saing dengan industri-industri lainnya.

\section{KAJIAN LITERATUR}

\section{Generasi Milenial}

Generasi millennial memiliki karakteristik yang berbeda dengan generasi $x$ dan generasi lainnya yang lebih tua. Karena generasi millennial lebih akrab dengan teknologi berbasis digital dan juga internet. Millenials juga disebut sebagai generasi instan karena generasi millennial identik dengan segala sesuatu yang instan, dan sangat mengandalkan teknologi dalam segala hal dimulai dari kerja, belajar maupun dalam keseharian hidupnya. Selain itu karakter lain dari generasi ini adalah sangat menyukai mempelajari hal- hal baru, kreatif, selalu mencari tantangan, generasi bebas yang dapat bertanya dimana saja lalu memilah opini yang akan berguna baginya, dan memiliki kesempatan yang tidak terbatas.

Kreativitas yang ada pada generasi millenials ini berarti memiliki kemampuan untuk menciptakan sesuatu yang baru. Industri kreatif sekarang merupakan industry yang sedang berkembang dan dapat meningkatkan perekonomian Negara secara keseluruhan. Pada tahun ini Joko Widodo menargetkan pertumbuhan ekonomi mencapai $5.4 \%$ target ini ditingkatkan dari tahun 2018 sebesar 5.1\%. Yang berarti pertumbuhan ekonomi ini dapat ditandai sebagai mulai majunya ekonomi kreatif di Indonesia. Ekonomi kreatif ini tidak muncul secara tiba-tiba. 
Sebelumnya ada beberapa era dalam peradaban manusia yang telah dilewati sebagian masyarakat di seluruh dunia. Ketika satu era sudah tidak mendukung lagi, lahir era baru sebagai alternatif. Era ini dapat dilihat dari kegiatan ekonomi yang dilakukan manusianya.

Perilaku dan pola konsumsi dari Generasi sekarang penting untuk diamati dan dikenali terutama dalam hal keputusan bisnis dan arah ekonomi ke depan. Jika kita tidak menyesuaikan diri akan perubahan, maka kita akan cenderung tertinggal. Potensi dan tantangan masa depan perekonomian Indonesia dianggap menjadi salah satu faktor pendorong transformasi ekonomi digital. Selain itu, dari sisi demografi Indonesia yang didominasi oleh anak muda diharapkan dapat menciptakan inovasi dan kreasi yang mampu meningkatkan perekonomian dalam negeri.

\section{Limbah Kayu}

Di Indonesia terdapat tiga macam industri kayu yang secara dominan mengkonsumsi kayu dalam jumlah relatif besar, yaitu penggergajian, vinir/kayu lapis dan pulp/kertas. Yang menimbulkan masalah adalah limbah penggergajian yang kenyataannya dilapangan masih ada yang di tumpuk sebagian dibuang ke aliran sungai (pencemaran air), atau dibakar secara langsung (ikut menambah emisi karbon di atmosfir). Menurut Forestry Statistic of Indonesia 1997/1998, Produksi total kayu gergajian Indonesia mencapai 2.6 juta m3 per tahun .Asumsi bahwa jumlah limbah yang terbentuk 54.24 persen dari produksi total maka dihasilkan limbah penggergajian sebanyak 1.4 juta m3 per tahun; angka ini cukup besar karena mencapai sekitar separuh dari produksi kayu gergajian.

Adanya limbah yang dimaksud menimbulkan masalah penanganannya yang selama ini dibiarkan membusuk, ditumpuk dan dibakar yang kesemuanya berdampak negatif terhadap lingkungan sehingga penanggulangannya perlu dipikirkan. Salah satu jalan yang dapat ditempuh adalah memanfaatkannya menjadi produk yang bernilai tambah dengan berbagai teknologi yang ada.

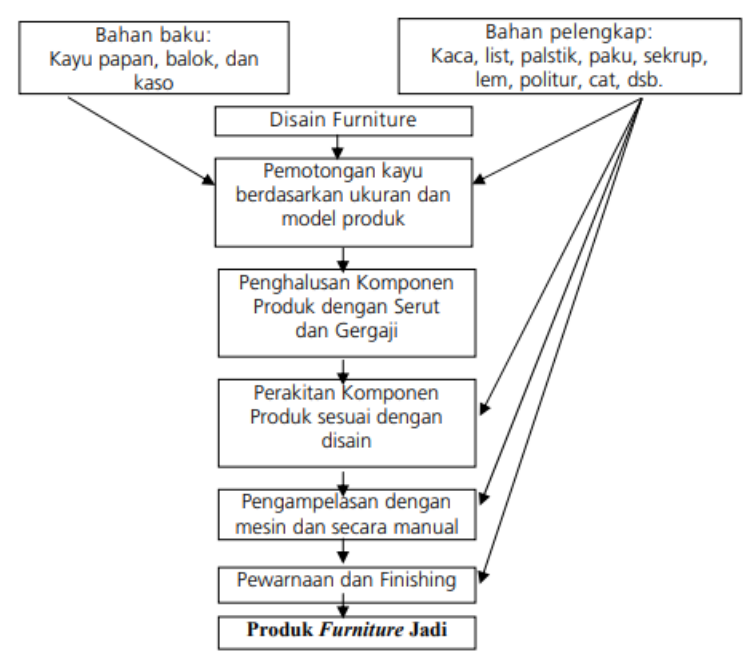

Gambar 1 Proses pembuatan daur ulang kayu Sumber : Bl.go.id - Usaha Furniture Kayu

Proses produksi pada usaha kecil furniture kayu ini menggunakan teknologi proses sederhana secara manual untuk pekerjaan kecil dan rinci. Pada pekerjaan yang lebih berat sudah menggunakan teknologi proses semi modern, yaitu dalam proses pemotongan, penyerutan dan penghalusan untuk bidang-bidang yang lebih luas.

Proses pembuatan furniture kayu merupakan gabungan proses mekanik (pemotongan, pengeboran dan pemolaan kayu) dan pengerjaan seni (pembentukan akhir sesuai contoh 
model). Furniture kayu yang dihasilkan merupakan produk yang mempunyai kandungan seni menurut model dan fungsi produk yang dikehendaki. Proses pembuatan dilakukan melalui beberapa tahapan yaitu pemotongan kayu gelondongan menjadi bentuk kaso, papan dan balok yang dilakukan di tempat penjual kayu.

Selanjutnya bahan tersebut dilakukan pemotongan sesuai dengan ukuran produk, pembentukan model-model produk dengan mesin bubut, pengukiran bentukan produk jadi, pengampelasan, pewarnaan dan finishing. Pewarnaan umumnya memanfaatkan warna alami kayu jati yang sangat digemari oleh konsumen. Penguatan warna sesuai selera konsumen, biasanya cenderung kepada warna terang

\section{Fasilitas Kreatif}

Berfokus pada penyediaan ruang bagi insan kreatif untuk berkarya dan berkegiatan, creative hub didefinisikan sebagai tempat penelitian dan pengembangan, belajar, dan membuat prototipe produk. Setiap pusat kreatif memiliki keunikan tersendiri, karena ditentukan oleh penempatan geografis, konteks budaya, persyaratan komunitas, dan model pendanaan unik. Creative Hub ini pada akhirnya menjadi 'sarang bagi freelancer dan UKM mikro untuk berkumpul (Prof. Andy Pratt: City, University of London).

Dengan adanya fasilitas kreatif ini dapat membuat para start up ini menjadi bagian dari suatu organisasi. Yang pada biasanya biasanya bekerja dari rumah, dapat terhubung, berkolaborasi, dan berbagi dengan orang-orang yang berpikiran sama. Menjadi bagian dari komunitas meningkatkan kepercayaan diri, eksperimen, kolaborasi, dan pertumbuhan pekerja lepas. Bersama-sama mereka dapat bekerja, mengakses sumber daya dan alat, menginspirasi satu sama lain dan menarik investasi sebagai kumpulan disiplin ilmu.

Ruang penting yang terdapat di fasilitas kreatif ini :

A. MAKER SPACE

Ruangan ini memiliki beberapa fasilitas atau peralatan yang digunakan untuk membuat suatu produk. Peralatan yang dapat ditemukan di ruangan ini antara lain mesin woodworking, mesin $3 d$ printing, mesin laser cutting dan juga mesin- mesin lainnya.

B. WORKING SPACE

Ruangan ini digunakan untuk bekerja bagi startup baru yang sedang mengembangkan bisnisnya. Tempat ini dibuat dengan tujuan agar selain start up itu mengembangkan bisnisnya, terdapat juga fasilitas mengenai pendanaan, bimbingan, networking agar bisnis yang sedang dibangun dapat berkembang lebih maksimal.

C. RUANG PAMERAN (EXHIBITION SPACE)

Tempat untuk memamerkan produk- produk yang telah diproduksi

D. RUANG WORKSHOP (CLASSROOM)

Ruang ini dapat digunakan untuk berbagai kegiatan workshop seminar maupun talk show. Ruang kelas ini dapat menampung $15-20$ orang

E. COMMERCIAL AREA

Tempat untuk menjual produk- produk yang telah diproduksi. Dengan konsep seperti marketplace untuk memberikan kemudahan bagi pembeli untuk mendapatkan barang yang dibutuhkan lebih cepat.

F. LIBRARY

Terdapat banyak buku untuk mencari info dan ide seperti buku design , bisnis maupun self development.

Di Indonesia ini, terdapat banyak Creative center yang telah terbangun di Indonesia beberapa di antaranya yaitu Bandung Creative hub yang dinaungi oleh Dinas Komunikasi dan Informatika (Deskominfo) dan Jakarta Creative Hub yang di naungi Dewan Kerajinan Nasional dan Badan UMKM yang didukung oleh wali kota dan Badan Ekonomi Kreatif ( Bekraf ). Creative 
center ini menjadi wadah yang memfasilitasi para pemuda kreatif dan para pelaku start up yang dilengkapi dengan sarana pendukung untuk kegiatan komunitas, office dan maker space.

\section{METODE}

Metode yang digunakan dalam perancangan proyek ini adalah dengan metode deskriptif analisis, metode deskriptif analisis ini merupakan suatu metode yang merupakan paparan atau deskripsi atas fenomena yang terjadi. Pola pengembangannya yaitu dengan melakukan beberapa tahapan analisis yang disertai dengan studi literatur yang mendukung teori. metode komparasi juga dilakukan dalam proyek ini dengan cara membandingkan hasil temuan teoriteori dan studi-studi yang ada antara satu dengan yang lain. Perbandingan ini juga dilakukan dalam melihat contoh-contoh studi kasus yang telah terjadi, dengan tujuan agar mendapatkan benang merah dan klasifikasi-klasifikasi dari tema besar yang diambil, yaitu mengenai wirausaha di Ekonomi Kreatif.

Konsep yang digunakan untuk proyek ini dibuat mengalur, agar semua pengunjung dapat mengikuti kegiatan yang ada di dalam bangunan. Sirkulasi di dalam ruangan galeri pun akan dibuat menjadi one way trip ber. Alur yang ada berdasarkan kegiatan kegiatan utama yang perlu dilakukan.

Ruang Kerja yang selalu memiliki ruang komunal dan memiliki ruang terbuka hijau sebagai tempat kontemplasi, berdasarkan teori bahwa alam dapat menenangkan dan menambah konsentrasi.

\section{DISKUSI DAN HASIL}

Dari hasil pengumpulan data yang dilakukan penulis, diketahui bahwa permasalahan millenial yang ada adalah kurang adanya ruang yang mewadahi para startup -startup baru untuk mulai berkembang dan kurang adanya industri yang membantu dalam pengolahan limbah kayu yang ada Dimana limbah- limbah kayu yang ada biasanya hanya dibiarkan saja menjadi tidak berguna .

Program yang diusulkan adalah Fasilitas Kreativitas Daur Ulang Kayu dengan tujuan mengembangkan kawasan Klender tidak hanya menjadi pusat kawasan furniture tetapi juga menjadi Kawasan pengolahan daur ulang kayu yang pada saat ini belum banyak diwadahi di Jakarta. Fasilitas Kreatifitas Daur Ulang Kayu ini dengan menggunakan sistem pada pusat kreativitas dimana didalamnya terdapat tempat yang disewakan bagi para start up baru agar dapat lebih berkembang dalam memulai usahanya dan usaha yang dijalankan merupakan usaha dengan menggunakan bahan dari daur ulang kayu.

Lahan yang terpilih berada di Jalan Pahlawan Revolusi dengan luas $7797 \mathrm{~m}^{2}$. Lokasinya berada di jalan yang menghubungkan antara pondok bambu dan juga klender. Bagian belakang tapak berbatasan langsung dengan Permukiman warga .

Konsep utama dalam desain mengalur, agar semua pengunjung dapat mengikuti kegiatan yang ada di dalam bangunan. Sirkulasi di dalam ruangan area pameran pun akan dibuat menjadi one way trip. Alur yang ada berdasarkan kegiatan kegiatan utama yang perlu dilakukan. Seperti workshop, kelas dan seminar dan juga pameran yang ada.

Program utama dari tapak ini meliputi Kantor sewa, ruang produksi dan area komersial . Area Produksi dibuat dalam dua jenis yaitu Area produksi besar maupun sedang. Area Produksi Besar terletak pada satu massa tersediri yang terdiri dari 3 lantai dan pada setiap lantainya terdapat 2 area produksi. Setiap lantai memiliki akses yang dekat dengan lift barang sehingga mempermudah pemindahan barang produksi yang diperlukan. 


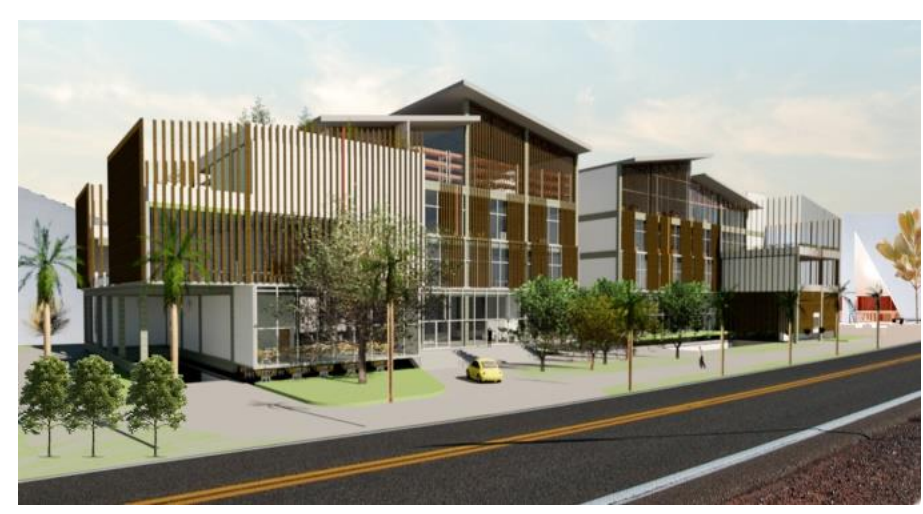

Gambar 2. Perspektif Eksterior

Sumber: Penulis, 2019

Program Ruang dihasilkan dari beberapa studi preseden yang merupakan kombinasi dari fungsi utama dan pendukung. Konsep yang diambil adalah tempat yang dapat digunakan oleh masyarakat khususnya wirausaha pemula untuk memulai usahanya serta untuk belajar mengenai daur ulang kayu dan juga pengolahannya.

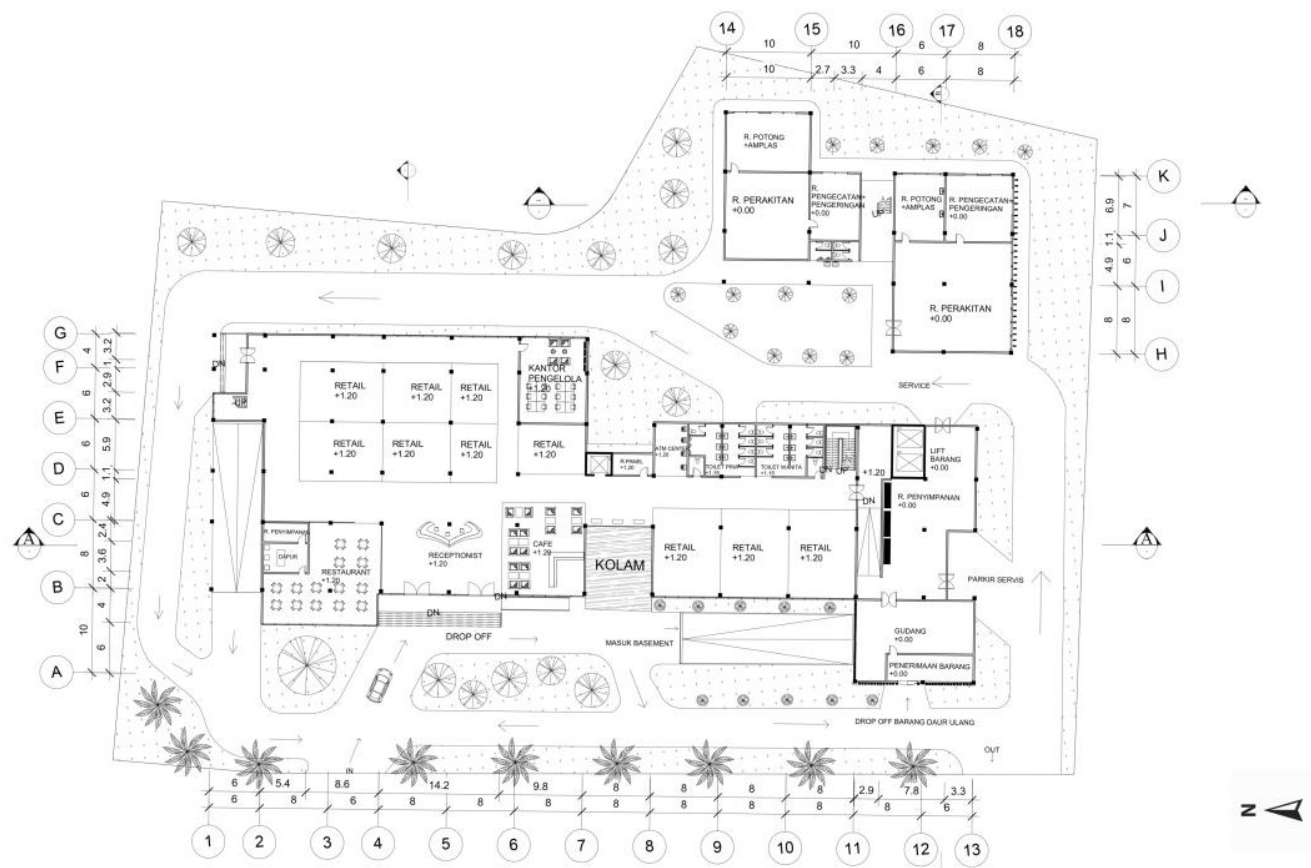

Gambar 3. Denah Lantai 1

Sumber: Penulis, 2019 


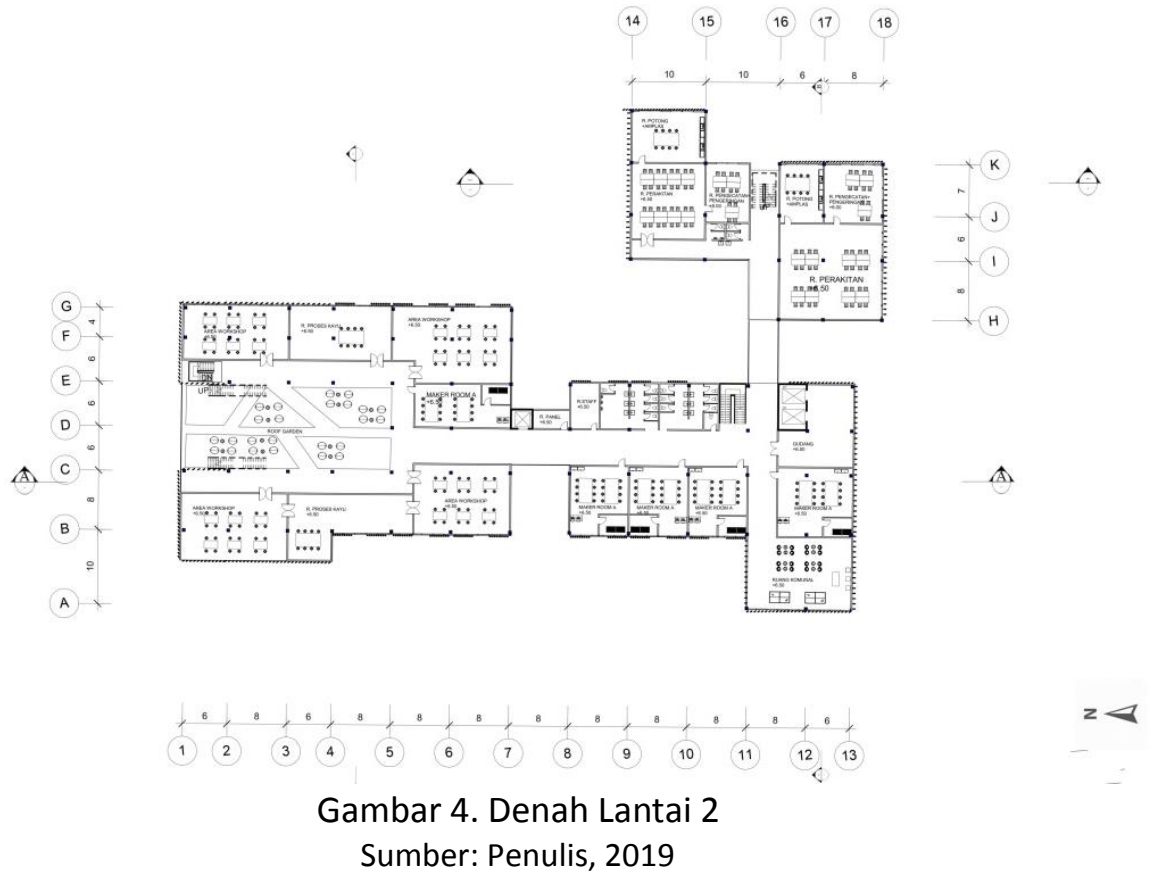

\section{KESIMPULAN DAN SARAN}

Proyek "Fasilitas Kreatifitas Daur Ulang Kayu " merupakan respon untuk menjawab permasalahan Generasi millennial yang ada . Permasalahan yang dimaksud meliputi Kurangnya lapangan kerja yang akan dihadapi sekarang hingga masa mendatang dikarenakan kurangnya generasi millennial yang ingin untuk berwirausaha dan juga semakin banyaknya limbah kayu yang ada sehingga kita harus menjaga lingkungan dengan cara mendaur ulang kayu- kayu yang ada sehingga menjadi barang yang lebih berguna. Diharapkan dengan adanya proyek ini, Wirausaha dalam bidang pengolahan limbah kayu dapat semakin banyak dan juga mulai semakin banyaknya masyarakat yang sadar akan lingkungan sekitar dan mulai untuk menggunakan produk daur ulang kayu ini

Desain proyek ini sekaligus dirancang untuk mencapai tujuan yang ada dalam "Sustainable Development Goals", dalam menjaga kebersihan lingkungan sehingga limbah - limbah yang ada dapat berkurang kedua yaitu menjamin akses ke energi yang terjangkau, andal, berkelanjutan, dengan bangunan yang hemat energi dengan memanfaatkan pencahayaan dan penghawaan alami. Dan menjadikan kota dan area kerja bagi generasi kita yang inklusif, aman, tangguh, dan berkelanjutan, dengan memastikan keberadaan fasilitas yang memadai dalam proyek ini seperti ruang hijau, dan ruang komunal.

Diharapkan modul dari proyek perancangan ini dapat berguna untuk pembuatan bangunan kreatifitas daur ulang kayu lainnya

\section{REFERENSI}

Agudin, L. M. (1995). The Concept of Type in Architecture: An Inquiry into the Nature of Architectural

Ali, H. (Februari 2016). The Urban Middle Class Millenials . Diunduh 17 Februari 2019, dari reseach gate https://www.researchgate.net/publication/314448735_Indonesia_2020_The_Urban_Mi ddle_Class_Millenials 
Advertorial. (2018). Dalam Artikel "Bisnis social ala kaum muda” https://tirto.id/bisnis-sosialsekarang-cHZU. diakses tanggal 20 februari 2018

Attard, A. (2010) et all.Â Student Centred Learning, Toolkit for students Staffs, and Higher Education Institution. Education International and the European Student Union, Brussel, Belgia, 2010.

Bella, A. (November 2018) Seperti Apa Tren Perilaku Konsumen Indonesia. Diakses 12 Juli 2019, dari marketeers: http://marketeers.com/seperti-apa-tren-perilaku-konsumenindonesia/

Cahyandari, D. (2007). Pemanfaatan limbah kayu sebagai bahan dasar pembuatan papan partikel. Traksi, Vol. 5 (1), $26-34$.

Genchev, Y. \& Marinova, M.(2013). Trends in modern home interior and furniture.

https://www.wartaekonomi.co.id/read182060/hipmi-sebut-jakarta-timur-miliki-potensi-jadiindustri-kreatif.html

https://id.wikipedia.org/wiki/Klender,_Duren_Sawit,_Jakarta_Timur

Journal of Wood Science, Design and Technology. Vol. 2 (1), 28-33

Jurnalis (Februari 2015).Social Entreprise inovasi untuk mengentaskan kemiskinan. Diunduh 17 Februari 2019, dari kompak :http://kompak.or.id/id/highlights/read/social-enterpriseinovasi-untuk-mengentaskan-kemiskinan-dan-membangun-ekonomi-inklusif

Kertajaya, H. (2018). Citizen 4.0. Gramedia Pustaka Utama. Smart City Jakarta diakses 17 maret 2019 http://smartcity.jakarta.go.id/maps/

Sutarman, I Wayan (Juni 2015). Pemanfaatan Limbah Industri Pengolahan Kayu . Diunduh 17 Februari 2019, dari media neliti : https://media.neliti.com/media/publications/182888ID-pemanfaatan-limbah-industri-pengolahan-k.pdf

Sartono K. (1987), "Gotong - royong: Saling Menolong Dalam Pembangunan Masyarakat Indonesia, dalam Callette, Nat.J dan Kayam, Umar (ed). https://www.academia.edu/36207303/Pancasila_Zaman_Now.pdf

Sukada, B. A. (1984). Tipologi Arsitektur Tradisional sebagai pendekatan dalam perencanaan dan perancangan kampus Universitas Indonesia di Depok, Jawa Barat

Swa media, Jurnalis. (24 Mei 2018).HIPMI Jaktim Dukung Pengembangan Industri Kreatif Jakarta. Diunduh 24 Maret 2019, dari SWA media: https://swa.co.id/swa/trends/hipmijak-tim-dukung-pengembangan-industri-kreatif-jakartaFadyl, Vicky (24 Mei 2018) HIPMI sebut Jakarta Timur memiliki potensi jadi Industri Kreatif. Diakses 12 Juli 2019, dari warta ekonomi: 